Int. J. Electrochem. Sci., 15 (2020) $10854-10865$

International Journal of

ELECTROCHEMICAL

SCIENCE

www.electrochemsci.org

\title{
Fabrication of Activated Carbon from Coconut Shells and its Electrochemical Properties for Supercapacitors
}

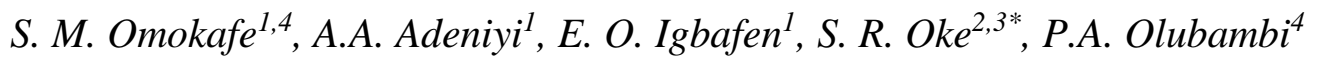 \\ ${ }^{1}$ Department of Metallurgical \& Materials Engineering, Federal University of Technology Akure, \\ PMB 704, Nigeria. \\ ${ }^{2}$ Department for Management of Science and Technology Development, Ton Duc Thang University, \\ Ho Chi Minh City, Vietnam \\ ${ }^{3}$ Faculty of Civil Engineering, Ton Duc Thang University, Ho Chi Minh City, Vietnam \\ ${ }^{4}$ Centre for Nanoengineering and Tribocorrosion, University of Johannesburg, Johannesburg, South \\ Africa \\ *E-mail: samuel.ranti.oke@ @ tdtu.edu.vn \\ *Corresponding author at: Ton Duc Thang University, Ho Chi Minh City, Vietnam
}

doi: $10.20964 / 2020.11 .10$

Received: 7 April 2020 / Accepted: 18 May 2020 / Published: 30 September 2020

\begin{abstract}
The problem posed by the use of fossil fuel energy and the increase in cost for energy storage materials, has led to the development of considerably cheap and environmentally friendly materials for energy storage. This has increased interest in biomass materials for synthesis of activated carbons, particularly as electrode materials for supercapacitor. For this research, coconut shell was utilized as a precursor material for the fabrication of activated carbon due to its availability, high carbon content, and the problem its disposal poses on the environment. Coconut shells were sourced locally, heated in a furnace, and activated using a two-step chemical activation with $1 \mathrm{M} \mathrm{H}_{2} \mathrm{SO}_{4}$ and $1 \mathrm{M} \mathrm{KOH}$. The activated carbon was compacted and subjected to a cyclic voltammetry test using varied scan rates of 20,40,60, 80 and $100 \mathrm{mV} / \mathrm{s}$, and a potential window between 0.05 and 0.8 . The specific capacitance at scanning rates of 20, 40, 60, 80 and $100 \mathrm{mV} / \mathrm{s}$ are 600.89, 299.78, 378.31, 374.13, and $286.92 \mathrm{~F} / \mathrm{g}$ respectively. The highest specific capacitance of $600.89 \mathrm{~F} / \mathrm{g}$ and energy density of $46.94 \mathrm{Wh} / \mathrm{kg}$ was obtained at a scan rate of $20 \mathrm{mV} / \mathrm{s}$. When compared with previous studies, the synthesized activated carbon electrodes from this research had the highest specific capacitance.
\end{abstract}

Keywords: Activated carbon; Coconut shell; Supercapacitor; Energy storage; Electrode FULL TEXT 
(C) 2020 The Authors. Published by ESG (www.electrochemsci.org )This article is an open access article distributed under the terms and conditions of the Creative Commons Attribution license (http://creativecommons.org/licenses/by/4.0/). 